\title{
Parentesco espiritual e afinidade potencial na América do Sul
}

DoI

http://dx.doi.org/10.11606/ 2179-0892.ra.2018.148952

\section{Helena Moreira Schiel}

- Universidade Federal do Oeste do Pará / Santarém, PA, Brasil

$\boldsymbol{\nabla}$ helenaschiel@gmail.com

\section{RESUMO}

No encontro colonial, duas formas de relação institucionalizada, as relações de compadrio cristão e as de afinidade potencial ameríndia, encontraram uma tal semelhança que puderam traduzir-se uma na outra. Partindo de uma leitura da sugestão de Salvatore D'Onofrio de um "átomo de parentesco espiritual" para explicar o compadrio, pretendo sugerir que as duas instituições evocam o mesmo tipo de armadura sociológica. Antes que a substituição do parentesco tradicional, acredito que o parentesco espiritual tenha uma relação de sobreposição e superação dos laços familiares. Avanço a hipótese de que esse tipo de relação institucionalizada estaria na base de toda relação política. palavras-chave

Parentesco, afinidade potencial, compadrio, política. 


\section{ABSTRACT}

By the colonial encounter, two kinds of institutionalized relations (Christian godparenthood and Amerindian potential affinity) have shown so much similitude that they could be translated in each other. Departing from an approach to Salvatore D'Onofrio's suggestion of a "spiritual kinship atom", I want to suggest that the two institutions evoke the same kind of sociological framework. More than the substitution of traditional kinship, I believe that spiritual kinship has a relation of superposition and a kind of overcome to family ties. I advance the hypothesis that this kind of institutionalized relation would be at the basis of every political relation.
The stranger or newcomer was adopted by means of reciprocal appelation of compère or commère. (...) Since the stranger usually assimilated himself to the group by marrying within this community, the terms compère and "brother in law" soon became synonymous, so that men allied by marriage usually called each other by the first term.

Claude Lévi-Strauss (1943: 408).

Todos esses fatos estão a esperar uma teoria do não-parentesco na América do Sul. Eduardo Viveiros de Castro (2002: 153).

No presente artigo' procuro demonstrar a pertinência em aproximar teórica e etnograficamente as relações implicadas no sistema de compadrio e aquelas implicadas nas manifestações da afinidade potencial ameríndia. Neste caso, chamarei atenção sobretudo para sua cristalização na figura dos "terceiros incluídos". Ambos fenômenos parecem articular uma abertura das relações de parentesco estritamente familiares às relações mais amplas e políticas². Por fim, sugiro como hipótese investigativa a possibilidade de estarmos diante de uma estrutura comum que se revelaria como uma espécie de "átomo da aliança política".

\section{COMPADRIO E PARAPARENTESCO AMERÍNDIO}

Em um artigo de 1943 sobre o uso de termos de parentesco entre os Nambikwara, grupo indígena do Brasil Central, Claude Lévi-Strauss mencionou as crônicas seiscentistas de viajantes franceses que descreviam as relações dos colonos com

\section{KEYWORDS}

Kinship,

Potential Affinity, Godparenthood, Politics
1 A versão inicial deste artigo foi apresentada como paper no simpósio "Antropología de los parentescos por elección" no $53^{\circ}$ Congresso Internacional de Americanistas, na Cidade do México. De longa gestação, o artigo contou com a generosa leitura e observações de Ricardo CavalcantiSchiel, Márcio Ferreira da Silva e Antonio Guerreiro Jr., bem como de pareceristas anônimos que contribuíram fundamentalmente para que as ideias desenvolvidas viessem a público. Eventuais equívocos são de minha inteira responsabilidade.

2 Não pretendo aprofundar o debate em torno das críticas a uma divisão entre doméstico e político nem sua versão generizada, como respectivamente domínios do feminino e do masculino, encontrada sobretudo nos trabalhos de Vanessa Lea (1993, 2012) para o Brasil Central e Marilyn Strathern para a Melanésia (1988). Entretanto, abordarei brevemente de que forma compreendo os domínios que estou chamando de "político" e "relações estritamente familiares". 
indígenas da costa brasileira. Naqueles relatos, um laço de parentesco institucionalizado era traduzido como compadrio (compérage). Para Lévi-Strauss, essa relação, que ele caracterizava como "tanto sexual como político-social" (1943: 398), havia sido negligenciada pelos autores por ser facilmente interpretada como análoga ou mesmo importada do compadrio ibérico. Ainda que tencionasse demonstrar que a relação era autêntica, ou seja, originária do sistema indígena de parentesco, Lévi-Strauss reconhecia sua grande semelhança com o sistema mediterrâneo.

Parece tentador deduzir dos relatos dos cronistas seiscentistas que naquele primeiro momento do encontro colonial duas categorias de parentesco de origem distinta foram reconhecidas como a tal ponto análogas que poderiam ser traduzidas uma na outra. Nas páginas que se seguem, procuro demonstrar que a armadura sociológica evocada nas relações de compadrio de tipo cristão se encaixa de forma tão adequada a um padrão ameríndio de socialidade ${ }^{3}$ que, em muitos dos lugares em que elas se encontraram, vieram a se fundir. Menos que o

3 Ver Strathern (1988) para a noção de "socialidade". sinal de um suposto declínio funcional das relações familiares preexistentes ao encontro colonial (Nutini e Bell, 1989: 417) ${ }^{4}$, acredito que a incorporação de uma instituição exógena como o compadrio pode ser, antes, fruto de uma sorte de predisposição sociológica do sistema original.

O compadrio é um tema clássico na antropologia da Europa mediterrânea, bem como naquela das extensões latinas do continente americano. Trata-se de assunto recorrente na etnologia indígena da Mesoamérica e da região andina da América do Sul, uma vez que nessas áreas etnográficas o fenômeno do compadrio adentrou as relações de parentesco indígenas de forma mais entranhada. Entretanto, o tema é virtualmente inexistente na etnologia das Terras Baixas da América do Sul. Nessa grande área etnográfica, o compadrio não parece ter tido a penetração que teve nas outras áreas da América indígena. Ainda assim, nos lugares onde se encontraram, as duas instituições se sobrepuseram. Por outro lado, no Brasil rural, a instituição é recorrente nas abordagens antropológicas das sociedades camponesas, como em Ellen Woortmann (1995).

Muitas abordagens ao compadrio no mundo cristão parecem ter sido de caráter funcionalista e simbólico. Ressalta-se, por exemplo, sua função de "reforçar" as relações e desigualdades sociais implicadas na patronagem, como argumentou Pitt-Rivers a respeito do fenômeno na Andaluzia (1987: 34). Nutini e Bell (1989), por sua vez, descreveram-no como substituto do parentesco tradicional em decadência. Uma contribuição recente às abordagens do compadrio, que parte da paisagem etnográfica siciliana, pareceu-me excepcionalmente original ao propor um "átomo de parentesco espiritual" construído por analogia ao átomo de parentesco lévi-straussiano. Trata-se do trabalho de Salvatore D'Onofrio, que será nosso ponto de partida nesta empreitada de aproximar as concepções
4 Estes autores sugerem "a importância crescente do compadrio como concomitante da importância minguante do parentesco" (Nutini e Bell, 1989: 417) 
envolvidas no compadrio daquelas relações de "afinidade potencial" na América indígena, tais como propostas por Eduardo Viveiros de Castro (2002).

\section{TABU DO INCESTO NA TEORIA DA ALIANÇA}

Sabe-se que Claude Lévi-Strauss renovou a maneira como a antropologia aborda os fatos de parentesco. Pretendo aqui retomar os elementos essenciais de sua elaboração que permitiram a formulação da analogia do átomo espiritual. Antes de Lévi-Strauss, o tabu do incesto, regra reconhecida como universal ${ }^{5}$, era interpretado apenas segundo seu caráter negativo, de proibição. A preocupação dos estudos funcionalistas de então era sobretudo voltada para os sistemas de filiação e descendência. Radcliffe-Brown considerava que a unidade estrutural do sistema de parentesco, o que ele chamava de "família elementar", era composta de pai, mãe e seus filhos (2013: 82). No entanto, a importância funcional da figura do "irmão da mãe" em inúmeras sociedades, fenômeno conhecido na literatura antropológica como "avunculato", intrigava os analistas de então (Radcliffe-Brown, 2013). Tanto em sociedades matrilineares, como patrilineares, 0 irmão da mãe aparece como peça-chave nas relações de parentesco, geralmente em contraste com as relações estabelecidas com o pai, revestidas seja do caráter de evitação, seja de relações jocosas.

Lévi-Strauss desloca o foco sobre o tabu do incesto de seu caráter negativo - a proibição - para o seu caráter positivo, qual seja, aquilo que ele chamou de "imperativo da troca": a aliança. Ao impedir que parentes consanguíneos se casem entre si (irmãos com irmãs, pais com filhos, etc.), o tabu do incesto impõe a abertura da mônada familiar à troca com o Outro. Na fórmula lévi-straussiana, um homem abdica de sua irmã (ou filha) em prol da troca com outro homem. Para Lévi-Strauss, portanto, a presença da figura do "irmão da mãe" é imediatamente dada. A relação avuncular seria o verdadeiro átomo de parentesco (Lévi-Strauss, 1973: 58). Este átomo seria composto de três relações que uniriam quatro elementos. Relação de consanguinidade, unindo irmão e irmã; relação de afinidade, unindo marido e esposa; e relação de filiação, unindo pai(s) e filho. Unidade mínima para a reprodução da sociedade, o átomo de parentesco seria logicamente anterior ao núcleo familiar da teoria da descendência, tal como proposto por Radcliffe-Brown.

Fato natural, porque universal, e fato cultural, por seu caráter de regra, o tabu do incesto foi considerado como "charneira", articulação lógica entre natureza e cultura, regra fundante da sociedade humana. Os intérpretes do avunculato jamais tentaram postular que ele fosse um fenômeno universal (Lévi-Strauss, 1958: 58), mas sim que sua armadura possuía um forte poder explicativo, sintetizando as relações em geral encontradas nos sistemas de parentesco:

5 Todas as sociedades proíbem o intercurso sexual entre parentes em algum nível. 
"Essas relações devem estar sempre presentes, mas os termos que elas unem podem mudar ou se multiplicar" (Lévi-Strauss, 1973: 106, ênfases minhas) ${ }^{6}$. Da mesma forma, os estudiosos do parentesco não pretendiam que essas relações abrangessem toda as relações numa sociedade. Com efeito, as relações de parentesco não são as únicas que se recobrem de regras, tabus e prescrições.

\section{TABU DO INCESTO NO ÁTOMO DE PARENTESCO ESPIRITUAL}

Pesquisando junto a comunidades da Sicília, no sul da Itália, o antropólogo Salvatore D'Onofrio observou que o encontro sexual entre a mãe de uma criança e o padrinho da mesma seria socialmente percebido como um grave insulto.

Dependendo do contexto, ele seria considerado ainda mais grave que a relação entre parentes consanguíneos tais como irmão e irmã, pai e filha (cf. o mito "Le Fils insatiable", D'Onofrio, 2004: 67). Esses dados sugeriram ao autor que poderíamos estar diante de uma espécie de "tabu do incesto espiritual". À parte o tabu imposto sobre o par compadre-comadre, lembremos que até recentemente havia uma proibição formal da parte da Igreja que impedia os próprios pais de se tornarem padrinhos de seus filhos, conforme Marcos Lanna (2009). Para Cudeman (1972) essa está entre as principais características do compadrio.

Salvatore D'Onofrio procurou demonstrar sobretudo que algumas funções atribuídas ao irmão da mãe em outras sociedades eram, na Sicília, atributo do padrinho. Esta segunda constatação sugeriu ao autor que o padrinho teria substituído, no horizonte cristão, a figura do irmão da mãe. Como se verá adiante, discordarei do autor neste ponto específico, nos seus termos de "substituição" do irmão da mãe. Sugiro em seu lugar uma sobreposição ou superação das relações convencionais de parentesco.

A conjunção de características das relações implicadas no parentesco estabelecido ritualmente levou D’Onofrio a propor um "átomo de parentesco espiritual". Segundo o autor, ao lado da "família conjugal" se forma uma "família simbólica" composta da mãe/comadre, do filho/afilhado, do pai/compadre e do padrinho/compadre ${ }^{7}$. A seguir reproduzimos a figura ilustrativa do tal átomo sugerida por D’Onofrio, com as relações e o sistema de vocativos nela implicados ${ }^{8}$.

O discurso mítico cristão considera o batismo, ou seja, o nascimento ritual, como a reprodução ritual do nascimento de Cristo. Desta forma, o

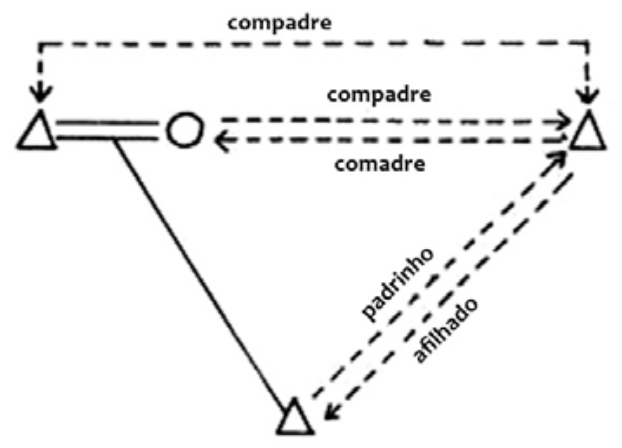

6 Citações que não estão originalmente em português foram traduzidas pela autora

7 Poder-se-ia objetar que estão excluídos dessa figura termos como "madrinha", por exemplo. No caso, reduzimos, com D'Onofrio, o átomo aos seus termos mais elementares. Entretanto, análises que queriam expandir e complicar esses termos poderiam levar tais elementos em consideração, sugerindo um sistema mais amplo.

8 Aqui, não é demasiado lembrar, os símbolos gráficos têm os seguintes significados: círculo equivale a uma mulher; triângulo, um homem; traço duplo, casamento; e traço vertical, filiação (aqui, diagonal, por comodidade de exposição gráfica). Seguindo D'Onofrio, introduzimos um sinal menos comum, o traço pontilhado, que significa relação de parentesco espiritual. Os vocativos acompanham os traços equivalentes.

\section{Figura 1}

Átomo de parentesco espiritual com vocativos (adaptado de D’Onofrio, 2004: 58). 
o papel de "Espírito Santo" no engendramento daquela criatura que está sendo batizada. D’Onofrio sugere que o batismo "segue e integra o nascimento biológico, conformando-se ao relato mítico da concepção virginal de Maria por obra do Espírito Santo" (2004: 59). Para o autor, "o batismo estaria para o nascimento natural assim como o nascimento miraculoso de Cristo, nascido de uma virgem, estaria para o nascimento normal" (2004: 61).

O nascimento, nas cosmologias ocidentais ${ }^{9}$, supõe lógica e cronologicamente uma concepção. Nesse caso, a concepção que serve de modelo para o discurso mítico é qualificada de "pura" ou "sem pecado", ou seja, assexuada. É esta concepção idealmente assexuada que será tentativamente reproduzida no ritual. O nascimento ritual advém de uma concepção, cuja qualificação por enquanto prefiro descrever como hesitação entre social e ritual, que engendra maternidade e paternidade rituais (compadrinhagem ${ }^{10}$ ). Porém, acredito que seja justamente nesta hesitação classificatória que reside a riqueza explicativa do quadro. Esse nascimento social/ritual, que introduz uma pessoa em uma comunidade eleita por seus pais, parece-me equivaler ao nascimento social propriamente dito. Independentemente de ser uma tentativa ritual de reprodução do nascimento divino e assexuado, ele implica uma espécie de superação da condição estritamente biológica de reprodução.

A escolha de um padrinho para o filho e, por consequência, a eleição de um compadre, significa a inserção do filho numa rede mais ampla de relações sociais, para além da família reprodutiva. Seja nas relações entre vizinhos, seja entre amigos ou ainda entre parentes distantes, o que está em jogo é a escolha de um conjunto de relações sociais. Não se escolhe a família em que se nasce, mas aos pais, sim, é possível escolher a família ritual à qual o filho vai pertencer"1. Adiante retornarei à qualificação dessa concepção, fundante e fundamental.

Para Salvatore D'Onofrio, o modelo da concepção virginal de Maria afirma "a superioridade dos laços espirituais e a impossibilidade de reproduzi-los no plano sexual" (2004: 61). Segundo a interpretação que ora proponho, se os homens não podem replicar, em suas existências ordinárias, a concepção ideal e milagrosa da Virgem, eles podem, ao menos, ritualizar uma concepção e um nascimento por meio do compadrio e do batismo.

O estudo comparativo dos sistemas de atitudes, ao lado dos sistemas de vocativos, no interior das relações familiares - que chamou a atenção dos analistas para a figura do irmão da mãe-permitiu a Lévi-Strauss empreender uma renovação aliancista nas abordagens ao parentesco. Por seu turno, a observação do sistema de atitudes no interior das relações de compadrio permitiu a d'Onofrio elaborar o átomo de parentesco espiritual.

Condutas e comportamentos estilizados, sugere Lévi-Strauss, podem estar servindo para expressar e sobrepujar "conflitos e contradições inerentes à es-
9 Não poderíamos nos furtar, aqui, de mencionar o "nascimento virgem" registrado na Melanésia, Austrália e sobretudo nas Il has Trobriand, que gerou uma certa polêmica nos anos 1960 e 70, a respeito da suposta ignorância dos povos "primitivos" a respeito do papel do pai na concepção (Leach, 1966). Os nascimentos virgens foram evocados novamente diante das novas tecnologias de reprodução, que permitem nascimentos sem concepção sexuada. Ver Delaney (1986) para uma revisão posterior sobre a primeira polêmica e Strathern (1995) para a segunda.

\footnotetext{
10 A junção dos termos compadrio e padrinhagem permitiu o neologismo "compadrinhagem" (compadrinazgo, em espanhol, comparrainage, em francês) sugerido por Ravicz para designar a relação em geral (tanto a vertical, a padrinhagem, quanto horizontal, o compadrio).

11 Não pretendo, com isso, filiar esta análise à alguma teoria da escolha racional, mas pôr em relevo a implicância sociológica da eleição do padrinho.
} 
trutura lógica, tal como se revela no sistema de vocativos" (1949: X). Retornando ao contexto etnográfico siciliano, D'Onofrio ilustra que a relação entre afilhado e padrinho, ou aquela entre compadres, extrapola as relações convencionais de parentesco. Há algo de especial ou de superior nas relações com esta figura externa que vem completar a composição do átomo de parentesco espiritual.

No sistema de atitudes marca-se um contraste entre a relação familiar estrita e aquela relação ritual, tal como evidenciado nos seguintes exemplos etnográficos. Amor de padrinho, amor fino, diz um provérbio siciliano, contrapõe-se a pai patrão (D'Onofrio, 2004: 65). Tal contraste já denota uma atitude positiva para com o primeiro e negativa para com o segundo. Esta relação diferenciada pode se encontrar especularmente invertida (e literalmente expressa) em outros contextos. Na própria Sićlia, indica D’Onofrio, é comum procurar o padrinho numa classe superior à da família de origem da criança. Essa característica, em outras paisagens etnográficas, pode dar origem justamente ao contrário do que sugere o provérbio italiano, ou seja, a fusão entre as figuras do padrinho e do patrão. Tal é o caso, por exemplo, da Andaluzia, conforme descrita por Pitt-Rivers. Para ele, o compadrio que, associado ao patronato, operaria sob o signo do "serviço" e da "proteção", teria por função justificar as desigualdades preestabelecidas socialmente ${ }^{12}$. No Brasil, a associação entre compadrio e patronato foi descrita por Marcos Lanna (1995). Em seus estudos das relações de dívida entre patrões e empregados no Nordeste brasileiro, Lanna sugeriu que o compadrio estaria na origem da assimetria hierárquica daquela relação.

Ainda na Sicília, a assimetria e o contraste dos padrões de atitude que diferenciam relações familiares e relações com a família espiritual estão evidenciados nas pequenas dádivas recebidas por uma criança na ocasião de seu aniversário. O padrinho deve se destacar oferecendo presentes mais caros ou mais vistosos do que aqueles oferecidos pelos tios ou pais da criança. Além disso, o padrinho tem o direito de intervir em casos de conflitos entre seu compadre e seu afilhado, ou seja, entre pai e filho. Fazendo uso de sua prerrogativa de "pai espiritual", portanto superior ao pai, o padrinho irá proteger seu afilhado. Este pode ameaçar o pai de "contar os fatos" ao padrinho (D'Onofrio, 2004: 65).

Para além das atitudes contrastivas nos pares de relação filho-pai e afilhado-padrinho, as relações entre compadre e comadre são revestidas de contrastes que denotam uma ambiguidade latente. Se o padrinho comparece ao átomo espiritual enquanto homólogo ao "Espírito Santo" na concepção "milagrosa" de Cristo, ele estaria imbuído, afinal, de um poder fecundante, ainda que séculos de trabalho simbólico tenham tentado destituir esta fecundação de seu caráter sexual ${ }^{13}$. Em alguns casos, o compadre/padrinho cumpre um papel de verdadeiro "operador da aliança", tal como registrado em várias regiões da Itália, em que se escolhe o padrinho para "favorecer o casamento do filho homem com a filha

12 Para uma abordagem crítica a essa explicação funcionalista, ver Lanna (2009).

13 Neste ponto específico, discordo de D'Onofrio em sua sugestão de que "das três relações canônicas previstas pelo átomo de parentesco: consanguinidade, aliança e filiação, é então a primeira que é substituída pela afinidade espiritual" (D’Onofrio, 2004: 64). O poder explicativo do átomo de parentesco está justamente no caráter de aliança estabelecida com o elemento estranho à família nuclear. Parece-me, portanto, improdutivo tentar colar termo a termo os dois tipos de átomo. A relação com o padrinho é uma relação de aliança que vai além da pura fundação da família e da troca matrimonial. 
daquele [o padrinho]" (D’Onofrio, 2004: 64). Esta relação, é ocioso notar, guarda forte analogia com o casamento entre primos cruzados, especificamente o de um Ego masculino com a filha do irmão da mãe. Outros aspectos da ambiguidade da relação entre compadre e comadre foram abundantemente descritos pelo autor. Uma mulher pode convidar para padrinho aquele, entre os amigos do marido, que a corteja, trazendo para a relação o interdito do incesto sem que eles percam uma certa intimidade que a relação jocosa proporciona. Ou, em outro exemplo,

O compadrio também se estabelece entre duas pessoas cuja relação adúltera resultou no nascimento de uma criança. Não há um vilarejo siciliano em que não se conte o caso de amantes que se tornaram, quase sempre por vontade expressa da mulher, compadre e comadre, e isso não para permitir uma proximidade maior, mas para interromper a relação sexual, submetendo-a à proibição do incesto (D’Onofrio, 2004: 77).

Por fim, destaco o papel de "sobreposição" às relações sociais convencionais de compadrio. $\mathrm{O}$ termo compadre é invocado em situações irregulares ou até ilícitas em que se demanda a cumplicidade da pessoa a quem se emite o vocativo de compadre. D'Onofrio cita situações no trânsito, em que se pede a paciência ou tolerância daquele "compadre" instantâneo. Ressalto, ainda, o contexto brasileiro, em termos como "apadrinhar" ou "padrinho político" que têm o significado de um favorecimento ilícito ou, ao menos, que extrapola as regras sociais convencionais. Voltaremos a este ponto ao evocar o alcance das relações de afinidade potencial na América indígena. Importa reter, por agora, o caráter de "amizade", de "boas intenções" e de assimetria no uso informal - não institucional - do termo compadre.

O trabalho simbólico elaborado na constituição do compadrio - que configura uma tentativa de superar a condição ordinária da reprodução social por meio de relações ritualmente estabelecidas, relações estas análogas ao parentesco - não é exclusivo do universo cristão. D’Onofrio destaca que a Igreja Católica tardou em reconhecer a ligação de compaternitas, que não consta dos Evangelhos. O termo patrinus, padrinho, diminutivo de pater, pai, só surge nos textos eclesiásticos no século VII (D’Onofrio, 2004: 58). Data do ano de 530 uma lei do Código Justiniano que interdita o casamento entre a mãe de uma criança e o padrinho da mesma. Tal constatação conduz o autor a suspeitar que a relação tenha origens ainda mais remotas, talvez pagãs: "Poderíamos concluir que somente as exigências do culto e as atitudes para com os costumes pagãos justificaram a progressiva admissão sistêmica do parentesco espiritual" (D'Onofrio, 2004: 59) ${ }^{14}$.

14 Esse questionamento sobre a origem pagã da padrinhagem se encontra também em outros autores, como Gudeman (1975) e Aland (1963). 


\section{AFINIDADE POTENCIAL NAS TERRAS BAIXAS DA AMÉRICA DO SUL: OS TERCEIROS INCLUÍDOS}

Algumas características do compadrio tal como abordado por D'Onofrio me pareceram evocar o fenômeno da afinidade potencial na Amazônia indígena e adjacências. Estas seriam, por exemplo, o encobrir de tabus e prescrições as relações internas ao "átomo espiritual", a sobreposição às relações convencionais, bem como o caráter de relação mediadora com a exterioridade.

Tal como faz notar Viveiros de Castro (2002) em seu artigo original de 1993, autores diversos reconheceram uma espécie de divisão no campo da afinidade amazônica e propuseram terminologias para dar conta do fenômeno. Em sua análise comparativa sobre o "problema" da afinidade na Amazônia, Eduardo Viveiros de Castro chama atenção para essa divisão: "O parente próximo, genealógica ou espacialmente, está para o parente distante como a consanguinidade está para a afinidade. Um afim efetivo é assimilado aos cognatos co-residentes (...) ao passo que um cognato distante é classificado como um afim potencial" (2002: 122).

Ele propõe, então, que se faça uma distinção entre o que ele chamou de afinidade efetiva ou atual (aquela dos cunhados e genros), a afinidade virtual cognática (daqueles que podem vir a ser afins tais como primos cruzados, tio materno) e finalmente, a afinidade potencial, ou sociopolítica (os cognatos distantes ou os não cognatos - voltaremos a essa categoria): "tudo se passa como se a afinidade efetiva fosse transformada em um caso especial da cognação. Já o afim virtual, concebido como afim potencial, é objeto de relações jocosas" (Viveiros de Castro, 2002: 131). A qualificação da afinidade potencial como sociopolítica será fundamental para a análise aqui proposta.

Em alguns casos, essa afinidade potencial tomaria forma na figura do que Viveiros de Castro chamou de "terceiros incluídos":

Os ternarismos inerentes ao regime amazônico de socialidade (consanguineos, afins efetivos ou aparentados, afins potenciais ou não-aparentados; cognatos, não-cognatos, inimigos) encontram uma manifestação clara naquilo que eu chamaria de 'terceiros incluídos' (...). Chama de fato a atenção, em quase todas as sociedades amazônicas, a importância de relações institucionalizadas que guardam referência complexa às atitudes de parentesco. (...) Tais posições ou relações não se caracterizam por uma mera exterioridade ao campo de parentesco, mas se articulam a esse campo de modos variados: inversão, neutralização, generalização, metaforização, e assim por diante. Na maior parte dos casos, esses terceiros incluídos (...) estão associados de modo privilegiado ao lugar simbólico da afinidade (2002:153). 
É preciso que nos detenhamos aqui sobre as primeiras coincidências com o parentesco ritual, tal como proposto por D'Onofrio. Nota-se, a partir dos dados etnográficos de D'Onofrio, o papel mediador do parentesco espiritual, entre a família e o seu exterior: a sociedade mais larga.

Como notado anteriormente, o termo "compadre" é frequentemente usado em situações ambíguas, em que se quer denotar boas relações com estranhos. Portanto, tal como a afinidade potencial, que é formulada a partir do parentesco e se projeta para fora do socius, o compadrio igualmente se projeta para o exterior, classificando virtualmente estranhos, pessoas não ligadas por laços de parentesco, àquele missivista que lhe remete o vocativo de "compadre". Viveiros de Castro ressalta que "O que os indo-arianos (e indo-europeus) fazem com 'irmão', os ameríndios tendem a fazer com 'cunhado', como qualquer especialista na região recordará" (2002: 152). Acrescento que o mesmo padrão de atitude se faz, no horizonte cristão, com o vocativo "compadre". Quero dizer que se utiliza o termo para designar pessoas não ligadas por aquela relação, na intenção de demonstrar boas intenções, afeto, respeito ou cumplicidade ${ }^{15}$.

Construídas por extensão ao domínio do parentesco, as relações rituais implicadas no compadrio guardam para com ele - sua "matriz" por assim dizer - uma relação de sobreposição. Na elaboração simbólica operada no mundo cristão ele toma o aspecto de superação ou superioridade. Esta assimetria e consequente hierarquização, que eleva o compadre a um patamar superior, torna-se mais evidente em contextos etnográficos tais como aquele analisado por Marcos Lanna, no Nordeste brasileiro. As figuras do padrinho e do patrão se fundem numa só pessoa, instaurando uma relação que está na origem da "dívida divina" do afilhado para com o seu padrinho (Lanna,1995).

Para Viveiros de Castro, a afinidade potencial abre a introversão localista do parentesco ao comércio com a exterioridade:

no mito e na escatologia, na guerra e no rito funerário, nos mundos imaginários do sexo sem afinidade e da afinidade sem sexo. Ela se "reduz" a uma pura relação, que articula termos justamente não-ligados por casamento. O verdadeiro afim é aquele com quem não se trocam mulheres, mas outras coisas: mortos e ritos, nomes e bens, almas e cabeças (2002: 157).

No caso do compadrio, se estou correta em interpretá-lo como uma forma análoga à afinidade potencial em outro contexto que não o mundo ameríndio, esse "verdadeiro afim", pura relação, é aquele com quem se trocam bens simbólicos, estabelecem-se dívidas e relações sobrepostas ao domínio do parentesco estrito.

15 Uma indagação que ficará em aberto é porque exatamente se evoca ora o "irmão", ora o "compadre", uma vez que ambos são categorias relevantes para o universo cristão. É possível que futuras descrições etnográficas venham a dar conta dessa variação.

\footnotetext{
Rev.antropol. (São Paulo, Online)|v.61 n. 2:187-207|USP, 2018
} 


\section{“TERCEIROS INCLUÍDOS” ENTRE OS GRUPOS JÊ}

A amizade formal foi reconhecida como uma das manifestações do fenômeno dos "terceiros incluídos" entre os povos de língua macro-jê do Brasil Central. Revelada sob o signo da solidariedade, bem como do respeito e evitação, os amigos formais fazem parte daquela categoria de "não parentes" que entram em cena nas atividades rituais e também fora delas. Guardam, por vezes, conexão com as proibições e preferências matrimoniais. É comum haver, por exemplo relações de evitação para com o amigo formal ao lado de relações jocosas com parentes do amigo formal. A amizade formal localiza o indivíduo numa rede de relações que se estende para além do seu círculo familiar doméstico.

Entre os Apinajé, a amizade formal introduz a criança em uma das metades cerimoniais. Assim como a escolha de um nominador (pessoa que atribuirá seu próprio nome à criança), a escolha do amigo formal é feita por uma categoria de pessoas a quem Roberto DaMatta (1976) chamou de "pais adotivos". Estes "pais adotivos", "arranjadores de nomes", são pessoas que fazem a intermediação entre a esfera estritamente doméstica e a esfera exterior da vida pública, mais formalizada.

Os Apinajé, tal como descritos por DaMatta, explicavam as relações da família nuclear com os "arranjadores de nomes", nos termos do compadrio cristão:

Os Apinajé traduzem essa relação como "padrinho/madrinha" "afilhado", revelando, assim, uma grande capacidade de observação dos costumes brasileiros regionais. Pois tanto em uma como na outra relação, as pessoas assim relacionadas devem se tratar com respeito e evitar referência a certos tópicos, como aqueles relacionados ao sexo (DaMatta, 1976: 141).

Foi também entre os Apinajé que Conçalves encontrou a relação de respeito/vergonha (piâm) admitida numa relação com os brancos quando encontrada numa situação de compadrio:

De todas as relações envolvendo os Apinayé e os brancos é esta a que parece apresentar maior estabilidade, e talvez seja, dentre todas, aquela que apresenta alguma dose de piâm, qualidade em princípio inexistente no conjunto das relações entre índios e brancos. O "respeito" e a "consideração" que deve existir entre os a tores implicados na relação de compadrio parece expressar essa qualidade. Assim, o compadrio entre índios e brancos estaria fundado em concepções distintas: uma Apinayé - baseada na relação interna à sociedade Apinayé entre "amigos formais" - e uma concepção regional - baseada na ideologia religiosa. Para finalizar: o compadre ou padrinho, assim como o "amigo formal" estaria numa 
posição liminar, fazendo a mediação entre as "fronteiras" da sociedade Apinayé e as da sociedade regional brasileira; incluir-se-iam entre suas a tribuições o estar presente quando dos momentos críticos experimentados por um indivíduo Apinayé no contex to de suas relações com a sociedade regional (Gonçalves, 1981: 62).
Trata-se de um exemplo em que as duas estruturas que quero mostrar análogas encontraram-se e se fundiram. Etnografia recente de Odair Ciraldin (2011: 424) com o mesmo grupo procurou mostrar que a amizade formal permite apagar traços de consanguinidade de uma determinada relação, quando se busca justamente a afinização. No caso, a amizade formal, seria o simétrico inverso da relação entre compadres na Sicília tal como descrita por D'Onofrio, no qual o compadrio é estabelecido para que pese sobre a relação os interditos do tabu do incesto.

Entre os Krahô, Manuela Carneiro da Cunha observou que se utiliza o termo nativo Hõpin para amigo formal entre pessoas não relacionadas por esse laço institucional. Sua utilização tenciona demonstrar amizade, como uma maneira de aproximar aqueles amigos - ainda-informais. É também lançando mão dos termos do compadrio cristão que os Krahô traduziam para Carneiro da Cunha a relação de amizade formal, Hõpin: "com muita propriedade, já que têm também regionalmente as conotações de respeito e solidariedade. Hõpin é o termo usado, em resumo, para os estranhos a quem se deseja marcar amizade ou simplesmente boas intenções" (Carneiro da Cunha, 1978: 75). Como se vê, vozes do século XVI ecoam no século XX. Tal como os Tupinambá a que o texto de Lévi-Strauss epigrafado no início deste artigo fazia referência, os indígenas contemporâneos encontraram no compadrio uma maneira de traduzir uma relação institucional de seu próprio sistema.

Entre os Karajá, grupo com o qual realizo pesquisa, a amizade formal foi descrita por Hans Dietschy nos anos 1950. Este autor registrou que os parceiros de dança - que dançam mascarados, em duplas, às vezes acompanhados de duas moças - que atuam nos dois grandes ciclos rituais do grupo, mantinham uma relação de amizade formal entre si. Essa amizade formal implicava em proibição do casamento com a irmã do amigo formal e em cooperação mútua ao longo da vida. Os amigos formais chamariam um ao outro pelo termo equivalente a "meu irmão mais novo"16 (Dietschy, 1960).

Quais concepções estariam por trás da amizade formal tal como descrita por Dietschy? Entre os Karajá, o universo é concebido como formado por três camadas sobrepostas. Um mundo subaquático, masculino e consanguíneo, de onde teriam surgido os humanos atuais. Trata-se de um lugar onde não há morte e nem fome. Por serem os habitantes imortais, é um espaço apertado, superlotado, as pessoas não se movimentam: estão sempre sentados em seus banquinhos. A reprodução é assexuada: basta jogar uma pedrinha para que
16 Atualmente, a amizade formal entre os Karajá parece ser apenas residual. Em pesquisa recente, notei que os parceiros de dança ainda são fixos, mas não encontrei nenhuma menção nativa a obrigações ou prescrições para com o parceiro de dança. A fixidez dos parceiros é explicada de forma prática: dançam juntos aqueles pares que "funcionam" juntos, ou seja, não erram o passo, o ritmo, não se desencontram na cantiga. O termo que Dietschy encontrou nos anos 1950 para o amigo formal ainda é utilizado tipicamente como um terceiro incluído: para denotar amizade mais próxima com um estranho: "como quando os tori [não-índios] chamam alguém de irmão quando não é irmão", me disse um Karajá. 
novas crianças apareçam (Toral, 1992). Outra camada é o mundo terrestre, onde vivemos. É um lugar caracterizado pela presença da morte e da alteridade. Para poder comer é preciso trabalhar e a reprodução é sexuada. Por fim, há a terceira camada, o mundo celeste. Trata-se de uma espécie de mundo perfeito em que todas os problemas advindos da afinidade estão resolvidos. Há homens e mulheres, consanguíneos e afins, mas a afinidade não é um problema. As pessoas estão sempre jovens e belamente adornadas. Não é preciso trabalhar para comer e o sexo é metafórico: os homens estão sempre dançando com suas companheiras, as adusidu (dançarinas) ${ }^{17}$. O mundo do céu seria um mundo de superação da afinidade enquanto problema ${ }^{18}$.

O mundo celeste da cosmologia karajá guarda semelhanças com o "céu" cristão em seus termos de perfeição e pelo fato de ser alcançado por meio de um certo "merecimento". O céu karajá só é "visitado" em vida por xamãs que só apresentam a face positiva do xamanismo: a cura. Os xamãs associados a esse patamar são considerados profundamente "bons". Em sua morte, esses xamãs ascendem ao mundo celeste e podem por vezes levar consigo seus parentes.

Tal como no compadrio cristão, sem poder viver esta "vida perfeita" do céu em suas existências ordinárias, os Karajá a reproduzem ritualmente. Em seu caso, essa reprodução é efetuada na dança das máscaras. É juntamente com o amigo formal, esse "irmão mais novo" que se performa a superação do mundo de afins.

Amigos formais, ou parceiros de dança, dançam com suas "irmãs classificatórias", as lerã. Trata-se de termo de parentesco utilizado para classificar afins potenciais. Como é comum nas manifestações amazônicas do dravidianato, o gradiente próximo/distante é responsável por determinar as afins potenciais, lerã teheriare (irmãs distantes) das irmãs efetivas, lerã tyhy (irmã "de verdade").

A dança também implica uma potencialização da fertilidade feminina. No mundo celeste, como mencionado, não há sexo literal, mas metafórico, e a afinidade é "perfeita", traduzida na dança com as irmãs. A mesma dança, na terra, é utilizada e mesmo recomendada como tratamento para casos de infertilidade. Mulheres que têm dificuldade de engravidar ficarão curadas ao dançar com as máscaras. Há, portanto, um deslizamento simbólico do caráter sexual e fertilizante da dança: negado no céu, afirmado em sua reprodução terrena.

Nota-se que, se por um lado o compadrio implica excluir as relações sexuais entre compadre e comadre, por outro a amizade formal karajá exclui a relação sexual com a irmã do amigo formal. No primeiro caso, como já foi demonstrado, trata-se de um "tabu do incesto espiritual". No caso karajá, pode-se ler o fenômeno como uma relação que se afirma como não-consanguinidade, ou seja, a amizade formal exclui parentes consanguíneos.

No compadrio, aparentemente estamos diante de um "tabu do incesto

17 O caráter de "sexo metafórico" da dança é largamente atestado pela etnografia. A dança chegou a ser sugerida como "rito de fertilidade" por Dietschy.

18 Para descrições mais amplas da cosmologia karajá, ver Rodrigues (1993) e Pétesch (2000) 
espiritual", resultante da consanguinização entre compadre e comadre. Por outro lado, na relação de amizade formal, teríamos uma relação que, ao mesmo tempo, afirma-se como não-consanguinidade ("amizade formal"), e não-afinidade (não se deve transformar o amigo formal em cunhado). Viveiros de Castro em seu artigo de 2002 notava que os terceiros incluídos se articulam ao campo do parentesco de modos variados: inversão, neutralização, generalização, metaforização e assim por diante. Se pudermos considerar o compadrio como uma variante da relação de afinidade potencial em outra paisagem etnográfica, não parece contraditório que, no caso particular da amizade formal jê, ele supere $o$ parentesco, modelando-se nele.

Fernando Santos-Cranero desenvolveu o tema da amizade, pouco explorado nas etnografias das Terras Baixas. O fenômeno teria sido ofuscado pela ênfase dada pelas etnografias às relações de consanguinidade e afinidade. A amizade intertribal, segundo o autor, é um meio de criar relações com Outros potencialmente perigosos. Em vez de os transformar em parentes ou afins, em certas ocasiões estes é que seriam transformados em amigos formais pessoais. "Neste sentido, pode-se afirmar que, ao menos em certas sociedades nativas da Amazônia, é a amizade, mais do que a afinidade potencial, que estrutura e engloba o parentesco" (Santos-Cranero, 2007: 15). Uma tentativa de articulação desta lógica com aquela do parentesco espiritual que estou propondo neste artigo certamente poderá iluminar dados etnográficos advindos da paisagem etnográfica amazônica.

\section{AFINIDADE POTENCIAL E COMPADRIO}

Naquelas sociedades ameríndias em que o cristianismo se entranhou mais profundamente, o compadrio parece ter efetivamente tomado o lugar do que Viveiros de Castro chamou de terceiros incluídos. Este é o caso dos Piro do Baixo Urubamba, tal como descrito por Peter Cow.

Nesse grupo, o batismo é visto como um momento privilegiado para se fazer compadres. Até mesmo aquelas pessoas que se declaram protestantes buscam os missionários católicos para batizar seus filhos. Entre os Piro, é raro que se escolham compadres entre pessoas de "classe" diferente. Os convidados são geralmente afins de afins (marido da irmã da esposa, por exemplo), preferencialmente um corresidente não-parente da mesma idade dos pais da criança a ser batizada (Cow, 1991: 175). O padrinho é aquele que segura a criança em seus braços enquanto é efetuado o rito. A relação entre compadres de mesmo sexo é de extremo respeito e ajuda mútua. Devem compartilhar a caça e não devem fazer piadas entre si (relações jocosas interditas). O intercurso sexual entre compadre e comadre é inimaginável: 
As relações implicadas no compadrio são recíprocas como aquelas entre afins de mesma geração, mas respeitosas como aquelas entre irmãos. Desta maneira, 0 compadrio transforma a valência das relações de parentesco para construir um relacionamento de quase-consanguíneo, quase-afim baseada em uma criança (Cow, 1991: 175).

O compadrio seria, nesse caso, uma maneira de reforçar relações entre corresidentes. "O nascimento de uma criança é utilizado para se substituir, em relações diádicas particulares, as relações de cuidado e atenção, remotas e esquecidas, que acabaram por fazer das pessoas, 'parentes distantes entre si'" (Cow, 1991: 175).

Em um artigo de 1997, "Parentesco como consciência humana", Peter Cow analisa o dispositivo de aparentamento dos Piro a partir de um mito. Cow descreve como o feto e o recém-nascido têm um status ambíguo. Neste povo, o momento do corte do cordão umbilical é aquele paradigmático na construção de relações. A relação entre compadres nasce de um ato tenso: o pai pede a um parente que corte o cordão umbilical e nesse ato nega o parentesco que pouco antes havia afirmado. O pedido é uma espécie de "(re-)afinização" de um consubstancial (com quem, aliás, as relações já eram próximas e "reforçadas" por atividades cotidianas). Logo em seguida ao ato de corte do cordão umbilical, as relações entre o pai da criança e o cortador e entre o cortador e a criança são recriadas em termos diferentes daqueles associados ao parentesco. Cow procura mostrar que os termos novos "substituem" os antigos termos de parentesco, resultando numa espécie de "hiperparentesco". Ou seja, o ritual de batismo não é exatamente um simples meio de reforçar relações entre corresidentes; é um ritual em que o parentesco é negado e recriado em outros termos.

Nos Andes Meridionais, mais especificamente numa comunidade indígena da região de Tarabuco (Bolívia) chamada Michkhamayu, o parentesco ritual também só se estabelece com o rito católico (Cavalcanti-Schiel, 2005: 129). Ali, no entanto, o que interessa é buscar padrinhos entre pessoas de fora da comunidade, gente da cidade ou mesmo de mais longe. Os padrinhos mais valorizados seriam aqueles que participam do rito de casamento (Cavalcanti-Schiel, 2005: 131). Tais padrinhos passarão a chamar e se referir ao casal como "afilhado" e "afilhada" e a seus pais como "compadre" e "comadre". No entanto, a relação de compadrio é mais extensiva. Ela faz parte, ao que tudo indica, de uma sociabilidade ideal, atingida na ebriedade das comemorações do rito:

A communitas instaurada pelo momento ritual e detonada pela ingestão compulsória de álcool consagra ou, antes, maximiza exemplarmente, a inclusão dessas anteriormente estritas externalidades. O compadrio implica, portanto, 
nessa gramática da inclusividade, qual seja, a da inclusividade potencial, ou se se preferir, da inclusividade como potencial (Cavalcanti-Schiel, 2005: 135).

Se na Amazônia, todo estrangeiro é um cunhado potencial, para a gente de Michkhamayu todo estrangeiro é um compadre potencial. E eles não hesitam em transformar estrangeiros em compadres reais: "De uma simbólica posição de 'distribuidor', o padrinho é transportado em vagas etílicas para uma abstrata parentalidade compartilhada como comunhão onde, à diferença da concepção ocidental e cristã de que, nesses momentos, somos todos 'irmãos', aqui seríamos todos compadres" (idem).

Note-se que o fenômeno dos terceiros incluídos se articula de maneiras diversas com o parentesco strictu sensu. Não existem apenas como (pura) exterioridade. Diversamente do compadrio, que estou sugerindo efetuar uma sobreposição e superação do parentesco, os terceiros incluídos são muitas vezes uma das condições do parentesco, uma vez que um parente é um "não-afim" logicamente antes de um afim ser um "não-parente".

Sumarizando sua proposta sobre a afinidade potencial, Viveiros de Castro ressalta que

para a lém dos juízos prescritivos da afinidade cognática (...) há um outro uso a priori reservado à afinidade potencial, que é o de pensar, isto é, socializar, o que está fora do Mesmo. Ao regime complementar da oposição entre consanguinidade e afinidade, submetido aos critérios do juízo formal analítico, é preciso sobrepor a suplementaridade inerente ao caráter sintético da afinidade potencial, lugar onde "algo acontece". A afinidade potencial é a primeira determinação sociológica da alteridade (Viveiros de Castro, 2002: 161).

Caberia perguntarmos o que ganham as etnografias regionais (aquelas do fenômeno mediterrâneo e aquelas da América do Sul) com a constatação de sua lógica similar? Como deve ter feito suspeitar a epígrafe usada no início do artigo, acredito que as duas espécies de fenômenos, se bem caracterizadas em seus aspectos de estabelecer uma abertura na mônada familiar, podem vir a desembocar no estabelecimento da tal "teoria do não-parentesco" que nos sugeriu Viveiros de Castro em 2002.

Trata-se de estabelecer uma hipótese sobre o alcance da relação-com suas variantes - que aqui propus aproximar, qual seja, a do compadrio cristão e da afinidade potencial ameríndia. Os dados apresentados justificam suspeitar que essa relação, estruturalmente idêntica uma vez que se a reduzam aos menores elementos, seja aquela que fundamenta a vida política. À etnografia caberia testar seu alcance, seu limite ou sua generalidade. 
Aqui é possível que sejam feitas objeções à maneira como estou tratando o conceito de "político" e seu par oposto, o "doméstico" ou "familiar". São bastante conhecidas as críticas ao par de opostos doméstico versus político ou mesmo sua manifestação generizada como domínios, respectivamente, do feminino e do masculino. Vanessa Lea mostrou como, para os Kayapó Mebengokre, o "centro" masculino da aldeia é englobado pela sua periferia feminina composta de "matricasas" detentoras de direitos (Lea, 1993, 2012). Em sua abordagem às representações do político nas Terras Baixas da América do Sul, Carlos Fausto procura demonstrar que, para os Parakanã, a Tekatawa - casa não residencial constituída como esfera pública onde decisões são tomadas e conflitos são mediados-pode ser interpretada como lugar próprio da ação política: "na ágora tudo deve-se passar como se apenas os interesses coletivos estivessem representados" (Fausto, 2001: 243). Para o autor, a sociedade se apresenta como totalidade na praça.

No caso que estou abordando, não me parece necessário realizar uma separação dicotômica entre doméstico e público e a assunção da primazia de um sobre o outro. Trata-se, aqui, de uma separação entre relações institucionalizadas na esfera familiar e relações que escapam ao domínio do familiar, a que chamei de políticas ${ }^{19}$.

Lévi-Strauss, em seu artigo de 1943, já apontava para o caráter "tanto sexual quanto político-social" da relação de compadrio (1943: 398, ênfases minhas). Viveiros de Castro, em vários momentos de seu texto, induz a essa formulação: "A afinidade potencial é um fenômeno político-ritual, exterior e superior ao plano englobado do parentesco" (2002: 159, ênfases minhas) e sugere, como na segunda epígrafe deste artigo, que esses fatos estão à espera de uma teoria das relações de "não-parentesco" na América do Sul.

Duas proposições analíticas recentes nos auxiliam a pontuar nossa argumentação com algumas breves observações finais. Marcos Lanna, em recente artigo sobre a estrutura sacrificial do compadrio, sugeriu mais explicitamente que esta seria a formulação fundante da relação política: "Conclui-se que o batismo e as obrigações entre compadres criam desigualdades políticas que obviamente diferem da dominação de classe, e que são inerentes à fundação da sociedade como realidade sagrada" (2009: 9). Marshall Sahlins, em sua interpretação do fenômeno dos "reis estrangeiros" - segundo a qual o poder, de modo geral, e os reis ou governantes, de forma particular, advém de um "exterior", seja cosmológico (reis divinos), seja espacial (reis estrangeiros) - sugere que as formas elementares do parentesco, da política e da religião seriam as mesmas (Sahlins,

19 É necessário mencionar que este artigo pode ser aprofundado em muitas direções que excederiam em demasia o tamanho razoável. Os caminhos são, por exemplo, aproximar a ideia de parentesco espiritual com a relação de couvade, série de tabus e medidas tomadas por um conjunto de parentes e/ou conhecidos quando do nascimento de uma criança. A proximidade da couvade com o compadrio foi notada por Peter Rivière em 1974 em artigo intitulado "The Couvade, A Problem Reborn". Por outro lado, os recentes avanços na compreensão das relações de maestria e domínio, desenvolvidas por Carlos Fausto e Luis Costa certamente acrescentariam profundidade etnográfica e analítica aos caminhos aqui esboçados. Com isso, manifesto a expectativa de que as ideias aqui desenvolvidas possam ser aprofundadas por pesquisas posteriores 2008: 197).

O tabu do incesto, segundo a interpretação lévi-straussiana, pertencia ao universo natural, por seu caráter universal (e, portanto, biológico) e, ao mesmo tempo, ao domínio da cultura, por seu caráter de regra, operando como arti- 
culação lógica entre natureza e cultura. De forma análoga, o tabu do incesto espiritual, ou a formulação daquela "pura relação", a afinidade potencial, pode ser sugerido como a articulação lógica entre o social e o político. É possível supor que essa interpretação possa se aplicar ao fenômeno da couvade, sugerido como forma ameríndia do tabu do incesto espiritual.

Parece-me que a relação de afinidade potencial seria uma charneira ou "articulação" entre os domínios ainda "contaminados" pela consanguinidade e aqueles mais exteriores do socius, seja a política, o sagrado ou a guerra (a inimizade). $O$ que quero dizer é que aquela relação que eu hesitara em qualificar entre social e ritual (ou espi-ritual), pode ser justamente a concepção que aqui estamos buscando. Sua ambiguidade me parece justamente a riqueza de seu significado: nem biológica nem sagrada, a concepção implicada no batismo é política, essa que está, portanto, à espera de uma "teoria de não-parentesco" para ser evidenciada.

Helena Moreira Schiel é professora assistente na UFOPA (Universidade Federal do Oeste do Pará), doutoranda em Antropologia Social na EHESS (Ecole des Hautes Etudes en Sciences Sociales, França). Realiza pesquisas junto aos Karajá desde 1999. Atualmente tem se interessado por relações de parentesco, guerra, cultura material e etnomusicologia.

\section{REFERÊNCIAS BIBLIOGRÁFICAS}

ALAND, Kurt

1963 Did the Early Church Baptize Infants? (trad. G.R. BeasleyMurray). Philadelphia, The Westminster Press.

CARNEIRO DA CUNHA, Manuela

1978 Os mortos e os outros. Uma análise do sistema funerário e da noção de pessoa entre os índios krahó. São Paulo, Hucitec.

CAVALCANTI-SCHIEL, Ricardo

2005 Da relutância selvagem do pensamento. Memória social nos Andes meridionais. Rio de Janeiro, tese de doutorado, Museu Nacional/ UFR]. 
COSTA, Luis

2013 "Alimentação e comensalidade entre os Kanamari da

Amazônia Ocidental". Mana, 19 (3): 473-504.

DELANEY, Carol

1986 "The Meaning of Paternity and the Virgin Birth

Debate". Man. New Series, v. 21, n. 3: 494-513.

DIETSCHY, Hans

1960 'Note à propos des Danses des Carajá. 'Pas de deux', Amitié formelle et proibition de l'inceste". Bulletin de la Société Suisse des Américanistes, Genebra, 19: 1-15.

1963 "Le Système de parenté et la structure sociale des indiens Carajá". Actes du Vle Congrès International des Sciences Anthropologique et Ethnologiques, Paris, Musée de l'Homme, tomo II, v. 1: 43-47.

FAUSTO, Carlos

2008 “Donos demais. Maestria e domínio na Amazônia”. Mana, 14 (2): 329-366.

GIRALDIN, Odair

2011 "Creating Affinity. Formal Friendship and Matrimonial Alliances among the Jê People and Apinajé Case". Vibrant, v. 8, n. 2: 403-426.

GONÇALVES, José Reginaldo Santos

1981 A luta pela identidade social: o caso das relações entre índios e brancos no Brasil Central. Rio de Janeiro, dissertação de mestrado, Museu Nacional/UFR].

COW, Peter

1991 OfMixed Blood. Kinship and History in Peruvian Amazonia. Oxford, Claredon Press.

1997 "Parentesco como consciência humana: 0 caso dos Piro". Mana, 3 (2): 39-65.

GUDEMAN, Stephen

1972 "The Compadrazgo as a Reflection of the Natural and Spiritual Person" Proceedings of the Royal Anthropological Institute, 1971, Londres: 45-71.

1975 "Spiritual Relationships and Selecting a Codparent". Man. New series, Londres, v. 10, n. 2: 221-237. 
LANNA, Marcos

1996 A divida divina. Troca e patronagem no Nordeste

Brasileiro. Campinas, Ed. Unicamp.

2009 "A estrutura sacrificial do compadrio: uma ontologia da

desigualdade?". Ciências Sociais Unisinos, São Leopoldo, 45 (1): 5-15.

LEA, Vanessa R.

1993 “Casas e casas Mebengokre (Jê)". In VIVEIROS DE CASTRO, Eduardo e CARNEIRO DA CUNHA, Manuela (orgs.). Amazônia: etnologia e história indígena. São Paulo, NHII-USP/Fapesp, pp. 265-282.

2012 Riquezas intangiveis de pessoas partiveis. Os Mebengôkre (Kayapó) do Brasil Central. São Paulo, EdUSP.

LEACH, Edmund

1966 "Virgin Birth". Proceedings of the Royal Anthropological Institute of Creat Britain and Ireland, Londres, issue 1966: 39-49.

LÉVI-STRAUSS, Claude

1943 "The Social Use of Kinship Terms among Brazilian Indians". American Anthropologist, New Series, v. 45: 398-409.

1949 Les Structures élementaires de la parente. Paris, Presses Universitaires de France: IX-XIV.

1958 Anthropologie structurale. Paris, Plon.

1973 Anthropologie structurale deux. Paris, Plon.

LOPES DA SILVA, Aracy

1986 Nomes e amigos: da prática xavante a uma reflexão sobre os ]ê. São Paulo, tese de doutorado, Universidade de São Paulo.

NUTINI, Hugo G. e BELL, Betty Louise

1989 Parentesco ritual: estructura y evolución histórica en la Tlaxcala rural. México, Editora Fondo de Cultura Económico.

PÉTESCH, Nathalie

2000 La Pirogue de sable. Pérénité cosmique et mutation sociale chez les karajá du Brésil central. Louvain/Paris, Peeters/Selaf.

RADCLIFFE-BROWN, Alfred Reginald

2013 "O irmão da mãe na África do Sul". In Estrutura e função na sociedade primitiva. Petrópolis, Vozes, pp. 21-34. 
RAVICZ, Robert

1967 "Compadrinazgo". In WAUCHOPE, Robert (org.). Handbook of Middle American Indians. Austin, University of Texas Press, pp. 238-252.

RIVIĖRE, Peter

1974 "The Couvade: A Problem Reborn". Man, 9 (3): 423-435.

RODRICUES, Patrícia de Mendonça

1993 O Povo do Meio. Tempo, cosmo e gênero entre os Javaé da Ilha do Bananal. Brasília, dissertação de mestrado, UnB.

SAHLINS, Marshall

2008 "The Stranger-King or, Elementary Forms of the Political Life". Indonesia and the Malay World, Routledge, Taylor \& Francis, Londres, 36 (105): 177-199.

SANTOS-GRANERO, Fernando

2007 "Of Fear and Friendship. Amazonian Sociality beyond Kinship and Affinity". Journal of the Royal Anthropological Institute (N.S.), 13: 1-18.

STRATHERN, Marilyn

1988 The Cender of the Gift. Berkeley, University of California Press.

1995 "Necessidade de pais necessidade de mães". Estudos

Feministas, Florianópolis, v. 3, n. 2: 303-329.

TORAL, André

1992 Cosmologia e sociedade karajá. Rio de Janeiro, dissertação de mestrado, Museu Nacional/UFR].

VIVEIROS DE CASTRO, Eduardo

2002 "O problema da afinidade na Amazônia". In A inconstância da alma selvagem. São Paulo, Cosac \& Naify, pp. 87-180.

Recebido em 31 de maio de 2017. Aceito em 6 de abril de 2018. 